\title{
Hubungan antara skala skor FOUR dan CT Marshall dengan penilaian GCS pada penderita cedera otak akibat trauma
}

\author{
Jemmy Matoha \\ Eko Prasetyo \\ Maximillian Ch. Oley

\begin{abstract}
Bagian Bedah Fakultas Kedokteran Universitas Sam Ratulangi Manado
Email: jemmy.matoha@yahoo.com
\end{abstract}

\begin{abstract}
Brain injury due to trauma is one of the main causes of deaths among traffic accident cases. This study was aimed to obtain the FOUR score scale and the CT Marshall, as well as to evaluate the relationships between FOUR score scale dan CT Marshall related to GCS in brain injury patients due to trauma. This was a prospective correlation study conducted at the Emergency Unit in Prof. Dr. R. D. Kandou Hospital Manado. There were 58 patients that fulfilled the inclusion criteria, consisted of 41 males $(70.7 \%)$ and 17 females (29.3\%). The correlation test of FOUR score and GCS score showed an $\mathrm{X}^{2}$ value of $77.215(P<0.001)$ meanwhile of the CT Marshall score and GCS score obtained an $\mathrm{X}^{2}$ value of $32.359(P<0.001)$. The correlation between FOUR score and CT Marshall score was tested with Spearman corrrelation test which showed $\gamma_{s}=-0.433(P<0.001)$. Conclusion: There was a statistically highly significant strong correlation between FOUR score and GCS score, but a statistically highly significant moderate correlation between CT Marshall and GCS. There was a statistically highly significant negative correlation between FOUR score and CT Marshall score.
\end{abstract}

Keywords: brain injury, trauma, FOUR score scale, CT Marshall, GCS

\begin{abstract}
Abstrak: Cedera otak akibat trauma (COT) merupakan salah satu penyebab utama kematian pada kasus-kasus kecelakaan lalu lintas. Penelitian ini bertujuan untuk menilai skala skor FOUR CT Marshall pada penderita cedera otak akibat trauma, dan menilai hubungan antara skala skor FOUR dan CT Marshall dalam menilai GCS pada penderita cedera otak akibat trauma Jenis penelitian ini ialah prospektif dengan pendekatan korelatif yang dilakukan di Intalasi Rawat Darurat Bedah (IRDB) RSUP Prof. Dr. R. D. Kandou Manado. Hasil penelitian mendapatkan 58 pasien yang memenuhi kriteria inklusi, terdiri dari 41 pasien laki-laki $(70,7 \%)$ dan 17 pasien perempuan $(29,3 \%)$. Uji statistik mengenai hubungan antara skor FOUR dan skor GCS (Cedera Kepala) mendapatkan $X^{2}=77,215(P<0,001)$. Uji statistik mengenai hubungan antara CT Marshall dan skor GCS (cedera kepala) mendapatkan $\mathrm{X}^{2}=$ 32,359 $(P<0,001)$. Pengujian hubungan skor FOUR dan CT Marshall dengan analisis korelasi Spearman mendapatkan $\gamma s=-0,433(P<0,001)$. yang menyatakan terdapat hubungan negatif yang sangat bermakna antara skor FOUR dengan CT Marshall. Simpulan: Terdapat hubungan kuat yang sangat bermakna antara skor FOUR dan GCS serta hubungan sedang yang sangat bermakna antara CT Marshall dan GCS. Terdapat hubungan negatif yang sangat bermakna antara skor FOUR dengan CT Marshall.
\end{abstract}

Kata kunci: cedera otak, trauma, skala skor FOUR, CT Marshall, GCS

Cedera otak akibat trauma (COT) merupakan salah satu penyebab utama kematian pada kasus kecelakaan lalu lintas. Di Inggris misalnya, setiap tahun sekitar 100.000 kunjungan pasien kerumah sakit berkaitan dengan trauma kepala; 20\% diantaranya terpaksa memerlukan rawat inap. Di Amerika Serikat, kejadian COT setiap tahunnya diperkirakan mencapai 500.000 kasus; $10 \%$ penderita meninggal 
sebelum tiba di rumah sakit dan lebih dari 100.000 penderita mengalami berbagai tingkat kecatatan akibat COT. ${ }^{1,2}$

Computerized tomographic (CT) scan, merupakan prosedur pilihan yang sering dipakai pada hampir seluruh senter pelayanan kesehatan, terutama untuk diagnosis, evaluasi, terapi, serta perkiraan prognosis pasien dengan cedera otak. Setelah pemakaian $C T$ scan, penggunaan foto kepala, angiografi, dan intervensi bedah menurun secara retrospektif. Pemeriksaan $C T$ scan ini tidak invasif sehingga dinilai aman dan memiliki akurasi yang tinggi. ${ }^{3,4}$

Pada tahun 1991, Marshall et al. mengusulkan klasifikasi CT untuk mengelompokkan pasien dengan cedera otak menurut beberapa karakteristik CT. Saat ini, klasifikasi CT ini merupakan metode prognostik yang paling sering digunakan, yang menggabungkan sifat anatomi cedera otak. CT Marshall menggunakan temuan dari $C T$ scan pada tingkat mesensefalik, tingkat pergeseran garis tengah, dan ada atau tidaknya lesi lokal. $^{3-5}$

Wijdicks et al. ${ }^{6,7}$ memresentasikan sebuah skala baru yaitu skor FOUR (Full Outline of UnResponsiveness) yang merupakan penggambaran keadaan tanpa respons secara lengkap, yang dikembangkan dan divalidasi dalam mengevaluasi kesadaran pasien dengan cedera otak. Terdapat 4 komponen yang dinilai dalam skor FOUR yaitu mata, motorik, batang otak, dan respirasi. Skor FOUR yang rendah dihubungkan dengan mortalitas saat dirawat di RS dan kecacatan pada pasien dengan trauma otak akut. Skor FOUR ini banyak memiliki keuntungan memberikan penilaian lebih detail pemeriksaan neurologik seperti refleks batang otak dan pergerakan mata dan juga mengenali herniasi unkal (uncal herniation), sindroma locked in, dan permulaan status vegetatif.,

Penelitian ini bertujuan untuk menilai skala skor FOUR dan CT Marshall pada penderita COT, dan untuk membuktikan hubungan antara skala skor FOUR dan CT Marshall dalam menilai GCS pada penderita COT.

\section{METODE PENELITIAN}

Jenis penelitian ini ialah prospektif dengan pendekatan korelatif yang dilakukan di Intalasi Rawat Darurat Bedah (IRDB) RSUP Prof. Dr. R. D. Kandou Manado mulai bulan Oktober sampai dengan November 2015. Kriteria inklusi ialah semua penderita COT sedangkan kriteria eksklusi ialah penderita cedera otak dengan multi trauma

Cedera otak adalah suatu gangguan traumatik dari fungsi otak yang disertai atau tanpa disertai pendarahan interstisial dalam substansi otak tanpa diikuti terputusnya kontinuitas otak. berikut:

Klasifikasi Skor FOUR ialah sebagai

- Skor FOUR 0-7: risiko mortalitas tinggi

- Skor FOUR 8-14: risiko mortalitas menengah

- Skor FOUR 15-16: risiko mortalitas rendah

Klasifikasi CT Marshall ialah sebagai berikut:

- Cedera difus I

- Cedera difus II

- Cedera difus III (pembengkakan)

- Lesi massa yang dievakuasi (V)

- Non-evakuasi massa(VI)

Klasifikasi GCS ialah sebagai berikut:

- 14-15 (ringan)

- 9-13 (sedang)

- 3-8 (berat)

\section{HASIL PENELITIAN}

Terdapat 58 pasien yang memenuhi kriteria inklusi, terdiri dari 41 pasien lakilaki $(70,7 \%)$ dan 17 pasien perempuan $(29,3 \%)$. Berdasarkan distribusi usia didapatkan usia terendah ialah 5 tahun sedangkan yang tertinggi 86 tahun (rerata 28,76 tahun). Nilai statistik skor FOUR yang terendah ialah 5 dan tertinggi 16 dengan rerata $14,40(\mathrm{SD} \pm 2,602)$.

Tabel 1 memperlihatkan bahwa berdasarkan skor FOUR terdapat mortalitas tinggi 3 orang $(5,2 \%)$, menengah 22 orang $(37,9 \%)$, dan rendah 33 orang $(56,9 \%)$. 
Tabel 1. Distribusi skor FOUR

\begin{tabular}{lcc}
\hline Skor FOUR & Frekuensi & Persentase \\
\hline Mortalitas tinggi & 3 & 5,2 \\
Mortalitas menengah & 22 & 37,9 \\
Mortalitas rendah & 33 & 56,9 \\
Total & 58 & 100,0 \\
\hline
\end{tabular}

Pada Tabel 2 didapatkan gambaran CT Marshall difus 1 sebanyak 13 orang $(22,4 \%)$, difus 2 sebanyak 40 orang $(69 \%)$, dan difus 3 sebanyak 5 orang $(8,6 \%)$.

Tabel 2. Distribusi CT Marshall

\begin{tabular}{ccc}
\hline CT Marshall & Frekuensi & Persentase \\
\hline Difus 1 & 13 & 22,4 \\
Difus 2 & 40 & 69,0 \\
Difus 3 & 5 & 8,6 \\
Total & 58 & 100,0 \\
\hline
\end{tabular}

Tabel 3 memperlihatkan bahwa yang tergolong cedera kepala $(\mathrm{CK})$ berat 4 orang $(6,9 \%)$, sedang 15 orang $(25,9 \%)$, dan ringan 39 orang $(67,2 \%)$.

Tabel 4 memperlihatkan hubungan antara skor FOUR dan skor GCS (Cedera Kepala) diuji dengan uji $\mathrm{X}^{2}$ sebab kedua variabel berbentuk data kategori. Hasil uji ini mendapatkan $\mathrm{X}^{2}=77,215$ dengan $P<$
0,001 yang menyatakan terdapat hubungan kuat yang sangat bermakna antara skor FOUR dan skor GCS pada penderita COT.

Tabel 5 memperlihatkan hubungan antara CT Marshall dan skor GCS (cedera kepala) diuji dengan uji $X^{2}$ sebab kedua variabel berbentuk data kategori. Hasil uji ini mendapatkan $\mathrm{X}^{2}=32,359$ dengan $P<$ 0,001 yang menyatakan terdapat hubungan sedang yang sangat bermakna antara CT Marshall dan skor GCS pada penderita COT.

Tabel 3. Distribusi cedera kepala

\begin{tabular}{ccc}
\hline Cedera kepala & Frekuensi & Persentase \\
\hline Berat & 4 & 6,9 \\
Sedang & 15 & 25,9 \\
Ringan & 39 & 67,2 \\
Total & 58 & 100,0 \\
\hline
\end{tabular}

Gambar 1 memperlihatkan pengujian hubungan skor FOUR dan CT Marshall dengan analisis korelasi Spearman yang mendapatkan ' $Y s=-0,433$ dengan $P<0,001$. Hasil ini menyatakan terdapat hubungan negatif yang sangat bermakna antara skor FOUR dengan CT Marshall. Makin tinggi skor FOUR maka makin rendah CT Marshall.

Tabel 4. Hasil uji hubungan skor FOUR dengan skor GCS

\begin{tabular}{lcccc}
\hline Skor FOUR & CK Berat & CK Sedang & CK Ringan & Keterangan \\
\hline Mortalitas tinggi & $3(75,0 \%)$ & $0(0 \%)$ & $0(0 \%)$ & \\
Mortalitas sedang & $1(25,0 \%)$ & $15(100 \%)$ & $6(15,4 \%)$ & $X^{2}=77,215$ \\
Mortalitas rendah & $0(0 \%)$ & $0(0 \%)$ & $33(84,6 \%)$ & $P<0,001$ \\
Total & 4 & 15 & 39 & \\
\hline
\end{tabular}

Tabel 5. Hasil uji hubungan CT Marshall dan skor GCS

\begin{tabular}{lcccc}
\hline CT Marshal & CK Berat & CK Sedang & CK Ringan & Keterangan \\
\hline Difus 1 & $0(0 \%)$ & $0(0 \%)$ & $13(33,3 \%)$ & \\
Difus 2 & $1(25,0 \%)$ & $13(86,7 \%)$ & $26(66,7 \%)$ & $X^{2}=32,359$ \\
Difus 3 & $3(75,0 \%)$ & $2(13,3 \%)$ & $0(0 \%)$ & $P<0,001$ \\
Total & 4 & 15 & 39 & \\
\hline
\end{tabular}




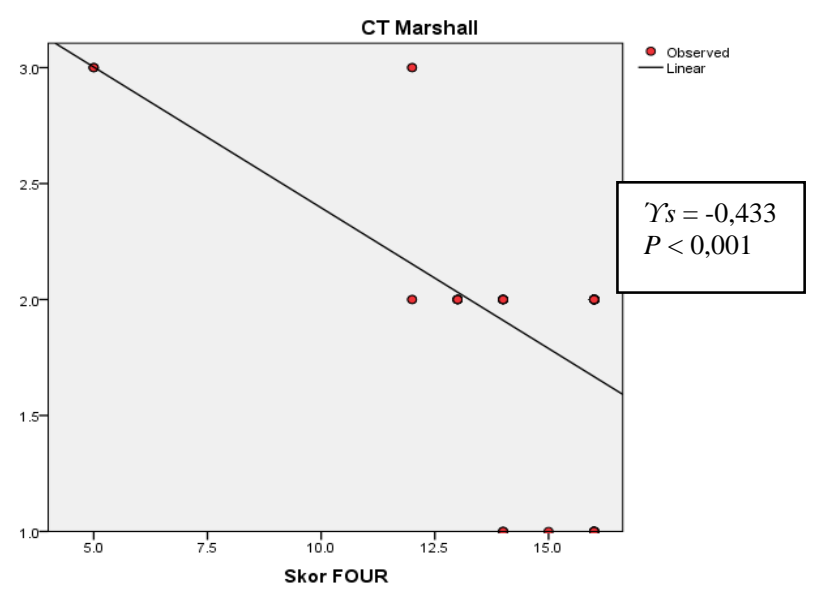

Gambar 1. Scatterplot hubungan skor FOUR dengan CT Marshall.

\section{BAHASAN}

Cedera otak akibat trauma (COT) merupakan salah satu penyebab utama kematian pada kasus kecelakaan lalu lintas. Meskipun dalam kenyataanya sebagian besar trauma kepala bersifat ringan dan tidak memerlukan perawatan khusus, pada kelompok trauma kepala berat tidak jarang berakhir dengan kematian atau kecacatan. Oleh karena itu, setiap petugas kesehatan diharapkan mempunyai pengetahuan dan keterampilan untuk melakukan penanganan pertama dan tindakan life saving sebelum melakukan rujukan ke rumah sakit. Diharapkan dengan penanganan yang cepat dan akurat dapat menekan morbiditas dan mortalitasnya. Penanganan yang tidak optimal dan terlambatnya rujukan dapat menyebabkan keadaan penderita semakin memburuk dan berkurangnya kemungkinan pemulihan fungsi.

Seiring dengan perkembangan jaman, ditemukan cara menilai berat ringannya keadaan pasien pada cedera otak, yaitu dengan skala CT Marshall, skor FOUR, dan GCS.

Skor FOUR dapat memberikan lebih banyak informasi dibandingkan GCS dengan penilaian empat komponen yaitu: penilaian refleks batang otak, penilaian mata, respon motorik dengan spektrum luas, dan adanya pola napas abnormal serta usaha napas, dengan skala penilaian 0-4 untuk masing-masing komponen. Dari penelitian Mangunatmadja ${ }^{8}$ mengenai perbandingan skor FOUR dan GCS, didapatkan bahwa terdapat hubungan yang sangat bermakna antara skor FOUR $<9$ dan GCS $<7$. Hasil ini sejalan dengan penelitian Wijdick et al. ${ }^{9}$ yang menentukan titik potong skor FOUR dalam hal prognosis kematian di rumah sakit ialah 9. Secara umum, nilai skor FOUR yang lebih tinggi menghasilkan luaran yang lebih baik. Risiko kematian tinggi (71\%) pada total skor FOUR 0-7; risiko sedang (20\%) pada total skor $8-14$; dan risiko rendah $(0,8 \%)$ pada total skor 15-16. Pada penelitian ini diperoleh hasil $\mathrm{X}^{2}=77,215$ dengan $P<$ 0,001. Hasil ini menyatakan terdapat hubungan kuat yang sangat bermakna antara skor FOUR dengan skor GCS pada penderita COT. Semakin tinggi mortalitas skor FOUR didapatkan semakin rendah nilai GCS, dan semakin rendah mortalitas skor FOUR didapatkan semakin tinggi nilai GCS.

CT scan telah terbukti menjadi penilaian utama dalam temuan patologik pada saat cedera kepala. CT Marshall menggunakan temuan dari CT scan pada tingkat mesensefalik, tingkat pergeseran garis tengah, dan ada atau tidak adanya lesi lokal untuk mengategorikan pasien menjadi enam kelompok yang berbeda. ${ }^{9}$

Skor FOUR dapat dipercaya dan valid untuk evaluasi kesadaran dengan beberapa konsekuensi menyangkut kepraktisan implementasi yang luas akan meningkatkan 
pengenalan skor. Skor FOUR ini dapat mengenali herniasi unkal, sindrom lockedin, permulaan status vegetatif, serta dapat menilai tentang keadaan respirasi terakhir dan bedanya dengan herniasi serebral. Terdapat hubungan bermakna antara skor FOUR dan CT Marshall. Risiko abnormalitas pada hasil CT Marshall pasien cedera otak meningkat seiring dengan bertambah rendahnya skor FOUR.

Hasil uji statistik menunjukkan bahwa terdapat hubungan sedang yang sangat bermakna antara derajat COT menurut GCS dan gambaran CT Marshall. Kendala GCS antara lain ialah pada penderita yang mengalami edema palpebra atau terintubasi, terdapat variabel yang tidak bisa dinilai. Ketika CT scan tidak tersedia maka GCS merupakan cara mudah untuk mengidentifikasi pasien yang memerlukan intervensi bedah. Risiko kelainan CT scan meningkat seiring dengan bertambahnya derajat cedera. Penelitian Bordignon dan Arruda $^{10}$ mendapatkan bahwa risiko kelainan CT scan pada pasien cedera kepala ringan lebih rendah yaitu 25,9\%. Terdapat hubungan bermakna antara GCS dan gambaran CT scan. Risiko abnormalitas pada hasil CT Marshall pasien cedera otak meningkat seiring dengan bertambah beratnya derajat GCS. Hasil penelitian oleh Farshchian et al. ${ }^{11}$ juga menegaskan bahwa semakin rendahnya GCS pada pasien COT semakin ditemukannya juga kelainan pada CT Scan.

Hal ini juga ditemukan pada hasil uji statistik penelitian ini yaitu hubungan antara CT Marshall dan GCS pada penderita COT sangat bermakna. Seiring berkurangnya nilai GCS, cedera difus pada CT Marshall makin bertambah berat. Sebaliknya, semakin bertambahnya nilai GCS, cedera difus yang ditemukan pada CT Marshall semakin berkurang.

\section{SIMPULAN}

Berdasarkan hasil penelitian dan bahasan dapat disimpulkan bahwa:

1. Terdapat hubungan kuat yang sangat bermakna antara skor FOUR dan GCS
2. Terdapat hubungan sedang yang sangat bermakna antara CT Marshall dan GCS

3. Terdapat hubungan negatif yang sangat bermakna antara skor FOUR dengan CT Marshall. Makin tinggi skor FOUR maka makin rendah CT Marshall.

\section{DAFTAR PUSTAKA}

1. Satyanegara, Cedera otak. In: Ilmu Bedah Saraf (3rd ed). Jakarta: Gramedia Pustaka Utama, 1988; p. 147-76.

2. American College of Surgeons. Advanced Trauma Life Support for Doctors. Washington: American College of Surgeon, 1997; p. 195-227.

3. Grumme T, Kluge W. Ceberal and Spinal Computed Tomography (3rd ed). Berlin: Schering AG, 1998; p. 49-63.

4. Naseri M, Tomasian A, Moghaddas AR. Correlation of CT scan findings with the level of consciousness in acute head trauma. Iran, J. Radiol. 2005;125.

5. Isherwood I. Radiology of head injuries. Neuroradiol. 2001;26:135-63.

6. Wijdicks EF, Bamlet WR, Maramattom BV, Manno EM, McClelland RL. Validation of a new coma scale: The score FOUR. Ann Neurol. 2005;58(4):585-93.

7. Wijdicks EF. Clinical scale for comatose patients: the Glasgow Coma Scale in historical context and the new score FOUR Rev Neurol Dis. 2006;3(3):10917.

8. Mangunatmadja DR, Yuniar I. Perbandingan full outlilne of responsiveness score dengan Glasgow Coma Scale dalam menentukan prognostik pasien saat kritis. Sari Pediatri. 2011;13(3):215-20.

9. Japardi I. Cedera Otak. Jakarta: Bhuana Ilmu Populer, 2004; p. 87-91.

10. Bordignon KC, Arruda WO. CT scan findings in mild head trauma: a series of 2,000 patients. Arq Neuropsiquiatr. 2002;60(2-A):204-10.

11. Farschian N, Farchian F, Rezaei $M$. Correlation between Glasgow coma scale and Brain CT-scan findings in traumatic patients. J Inj Violence Res. 2012;4(3 Suppl 1):44. 